\title{
Assessment of Dental Decay in a Group of Children in Jeddah, Kingdom of Saudi Arabia
}

\author{
Manal AL-Malik ${ }^{1}$, Hala AlKattan², Lujain ALBukhari ${ }^{3}$, Omar El Meligy ${ }^{4}$
}

\begin{abstract}
Aim: The purpose of this research was to determine the prevalence, severity, and pattern of dental decay in 6-7-year-old youngsters in military elementary schools in Jeddah, Kingdom of Saudi Arabia.

Materials and methods: The study included 312 youngsters randomly selected from eight elementary schools. Dental decay prevalence was determined by using $\mathrm{dmft} / \mathrm{dmfs} / \mathrm{DMFT} / \mathrm{DMFS}$ indices according to the "British Association for the Study of Community Dentistry" diagnostic specifications.

Results: There was no statistically notable difference in the prevalence of decay between boys and girls $(p=0.54)$. There was a notable difference between the mean $\mathrm{dmft}$ and $\mathrm{dmfs}$ in primary teeth $(p=0.000)$. There was a notable increase in the prevalence of decay for permanent teeth in males when compared to females $(p=0.011)$. The mean DMFT in boys was notably higher than that in girls $(p=0.035)$. No notable difference was found between males and females in mean DMFS $(p=0.54)$.

Conclusion: The prevalence of dental decay was high among the study sample. There is a vast need to reduce dental decay by increasing dental awareness for youngsters and their parents.

Clinical significance: Age has an important role in evaluating decay prevalence and dmft/dmfs/DMFT/DMFS indices. On the basis of age, caries is prevalent in 6-7-year-old youngsters and the $\mathrm{dmft/dmfs/DMFT/DMFS} \mathrm{indices} \mathrm{resulted} \mathrm{in} \mathrm{high} \mathrm{values.}$

Keywords: Children, Dental caries, Elementary schools, Prevalence, Severity.

International Journal of Clinical Pediatric Dentistry (2019): 10.5005/jp-journals-10005-1659
\end{abstract}

\section{INTRODUCTION}

During the past decades, the major concern arising from studies worldwide was the prevalence of dental decay. Dental decay is a persistent silent epidemic disease, affecting an individual's dental and general health negatively. ${ }^{1,2}$

It is significant for dental public health to recognize the level of oral health awareness, knowledge, and high level of dental decay so that the effort can be directed toward the prevention. Dental decay increased notably and is continuing to increase in populations. Generally, in primary dentition, the prevalence of dental decay in most developed countries is decreasing, while in developing countries is increasing rapidly. ${ }^{3}$

In spite of current enhancement in awareness about dental and oral health among public, dental decay continues to exist a notable complication mainly in growing countries. Youngsters in growing countries have an increased decay prevalence, such as China (85\%), India (53\%), and South Africa (49\%) when compared to developed countries such as England (32\%) and Italy (16\%). ${ }^{4-8}$

Dental decay is a multifactorial disease, with several risk elements contributing to their starting and progress. The risk elements can be classified as sociobehavioral, environmental, or biological. ${ }^{9-12}$

As Kingdom of Saudi Arabia is a multicultural, huge country, decay prevalence differs in its varying cities and districts. However, decay prevalence is increased in many districts and cities of Kingdom of Saudi Arabia. A novel research in Jeddah among preschool youngsters revealed an increased decay prevalence of $89 \% .^{13}$ Another investigation by Wyne in Riyadh showed a decay prevalence of $74.8 \%$ with a mean dmft score of 6.1 in preschool youngsters. ${ }^{14}$

The objective of the current research was to determine the prevalence, severity, and pattern of dental decay in 6-7-year-old
${ }^{1}$ Dental Department, King Fahd Armed Forces Hospital, Jeddah, Kingdom of Saudi Arabia

2,3 Dental Department, Private Practice, Jeddah, Kingdom of Saudi Arabia

${ }^{4}$ Pediatric Dentistry Department, Faculty of Dentistry, King Abdulaziz University, Jeddah, Kingdom of Saudi Arabia; Pediatric Dentistry and Dental Public Health Department, Faculty of Dentistry, Alexandria University, Alexandria, Egypt

Corresponding Author: Omar El Meligy, Pediatric Dentistry Department, Faculty of Dentistry, King Abdulaziz University, Jeddah, Kingdom of Saudi Arabia; Pediatric Dentistry and Dental Public Health Department, Faculty of Dentistry, Alexandria University, Alexandria, Egypt, Phone: +966 557521584, e-mail: omeligy@kau.edu.sa

How to cite this article: AL-Malik M, AlKattan H, ALBukhari $L$, et al. Assessment of Dental Decay in a Group of Children in Jeddah, Kingdom of Saudi Arabia. Int J Clin Pediatr Dent 2019;12(5):423-428.

Source of support: Nil

Conflict of interest: None

youngsters in military elementary schools in Jeddah, Kingdom of Saudi Arabia.

\section{Materials and Methods}

Ethical approval was obtained from the Medical Research Committee in the King Fahd Armed Forces Hospital, Jeddah, Kingdom of Saudi Arabia.

The sample was drawn from 6-7-year-old youngsters attending military elementary schools in Jeddah, the West Province of Kingdom of Saudi Arabia. Eight elementary schools for military dependents are present in Jeddah city, four schools for females and four for males. Each school had around 30-60 youngsters 
attending the first and second grade during 2017-2018. The study included a total of 312 youngsters ( 122 boys and 190 girls) randomly selected from all the schools. All youngsters selected participated in the clinical examination. The parents/caregivers of the selected youngsters were required to sign an informed consent form prior to the start of the study. All youngsters chosen shared in the clinical examination.

Clinical examination forms were developed and tested during the period of examiners calibration at the Dental Department, King Fahd Armed Forces Hospital. Selected investigators went through standardization meetings to unify inter- and intra-examiner reliability. Each investigator conducted 5 patients' examinations to evaluate dental decay, using $\mathrm{dmft} / \mathrm{dmfs} / \mathrm{DMFT} / \mathrm{DMFS}$ indices, respectively. ${ }^{15}$ Standardization meetings were done many times until the degree of uniformity reached $85 \%$ or more.

The dental team consisted of two general dentists and four dental interns. The examiners conducted clinical visual examinations in classrooms using a disposable examination kit and flashlight. Each child was examined in an upright position with the investigator positioned front and the data were written by a dental assistant. Sterilization and infection control guidelines were utilized at all examination locations to confirm protection of contributors.

Dental decay prevalence was determined by using $\mathrm{dmft} / \mathrm{dmfs} /$ DMFT/DMFS indices according to the "British Association for the Study of Community Dentistry" diagnostic specifications. ${ }^{16}$

\section{Statistical Analysis}

Data were analyzed utilizing SPSS (version 24; IBM, Armonk, NY, USA). Descriptive and analytic statistics in data analysis were used. The $t$ test was utilized to detect the difference between the mean $\mathrm{dmft}$ and dmfs in primary teeth and the mean DMFT and DMFS in permanent teeth and a $p$ value of less than 0.05 was regarded statistically significant. To detect the relationship between the prevalence of decay and gender in primary and permanent teeth, the Chi-square test was utilized.

\section{Results}

The study was done on a sum of 312 youngsters aged 6-7 years, 122 (39.1\%) were boys and 190 (60.9\%) were girls. In the 312 examined youngsters, the decay prevalence was found to be $88.8 \%$ (277 youngsters), while $11.2 \%$ (35 youngsters) were clinically decay-free. For those who were identified with decay, 110 (39.7\%) of them were males and 167 (60.3\%) were females. There was no significant difference $(p=0.54)$ in the prevalence of decay among boys and girls (Table 1 and Fig. 1).

The overall mean $\mathrm{dmft}$ for the 312 youngsters was $5.63( \pm 3.86)$ per child and the mean dmfs was $12.16( \pm 13.1)$ per child. These outcomes revealed a statistically notable difference in $\mathrm{dmft}$ and dmfs ( $p=0.000$ ) (Table 2, Figs 2 and 3).

Most of dental decay was made up of carious teeth. Carious teeth made up a medium of $4.54( \pm 3.74)$ teeth per child, which represented $80.6 \%$ of the total $\mathrm{dmft}$ and $7.95( \pm 9.38)$ surfaces per child, which represented $65.4 \%$ of the medium. Mean missing teeth was $0.58( \pm 1.75)$ per child and filled teeth were $0.86( \pm 1.59)$. Utilizing the independent-sample $t$ test, there was no statistically notable difference in the mean dmft and gender $(p=0.77)$ or the mean dmfs and gender ( $p=0.76$ ) (Tables 3 and 4, Figs 4 and 5).

The type of decay in primary teeth in these youngsters were analyzed. Collective information for the type of decay were shown; The teeth most influenced via decay were primary mandibular second molars (64.4\% and 66\%) and the least influenced were primary mandibular central incisors (1.7\% and $2.6 \%)$. The decay predominance was commonly higher in the mandibular primary teeth than similar teeth in the maxilla. Among the mandibular teeth, decay prevalence was the highest in second primary molars (65.2\%), followed by first primary molars (57.4\%) and primary canines (6.9\%). The mandibular primary central incisors were minimally influenced (2.15\%). Among the maxillary teeth, the prevalence was the highest in second primary molars (48.55\%), followed by first primary molars (43.6\%), primary central incisors (36.5\%) and primary lateral incisors (18.7\%). The maxillary primary canines were minimally influenced (10.3\%) (Table 5, Fig. 6).

Regarding permanent teeth, there was a notable increase in the prevalence of decay for permanent teeth in males when compared to females $(p=0.011)$. The mean DMFT was $0.26( \pm 0.68)$ and the mean DMFS was $0.36( \pm 1.16)$. The difference in the mean for DMFT and gender was statistically notable $(p=0.035)$ but insignificant for surfaces ( $p=0.54$ ) (Tables 6 to 8 and Figs 7 to 9).

The type of decay in permanent teeth in these youngsters were analyzed. Collective information for the type of decay were shown; The teeth most influenced via decay were permanent maxillary central incisors (14.4\% and $10.9 \%$ ) and the least influenced were permanent mandibular central incisors ( $0.5 \%$ and $0.5 \%)$.

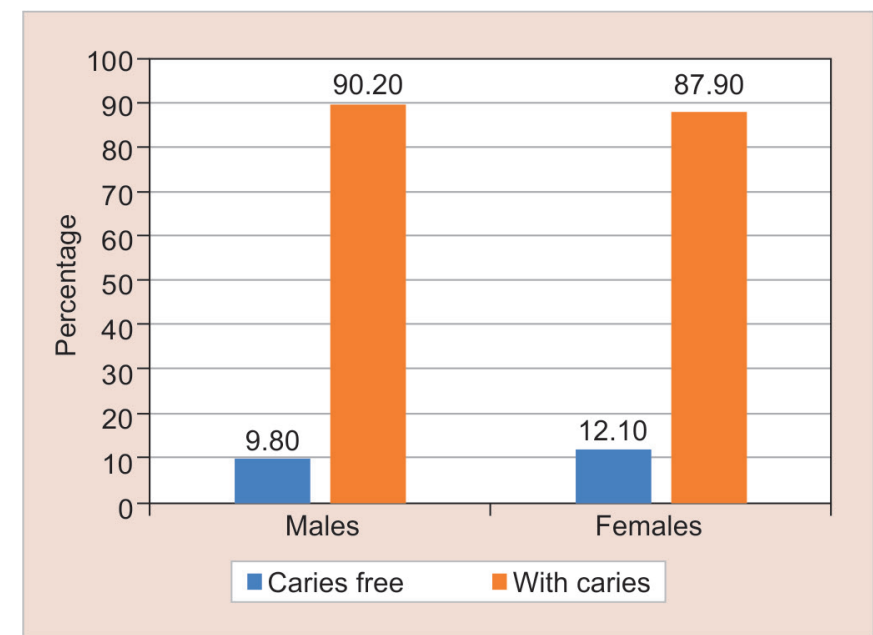

Fig. 1: Prevalence of caries in relation to gender for primary teeth

Table 1: Prevalence of caries, mean dmft, and dmfs in relation to gender for primary teeth

\begin{tabular}{|c|c|c|c|c|c|c|c|}
\hline Gender & No. of children & $\begin{array}{l}\text { Caries-free } \\
\text { children (\%) }\end{array}$ & $\begin{array}{l}\text { Children with } \\
\text { caries (\%) }\end{array}$ & $d m f t( \pm S D)$ & $d m f s( \pm S D)$ & $x^{2}$ & $p$ value \\
\hline Males & 122 & $12(9.8)$ & $110(90.2)$ & $5.71( \pm 3.78)$ & $12.44( \pm 14.10)$ & 0.38 & $0.54 \mathrm{NS}$ \\
\hline Females & 190 & $23(12.1)$ & 167 (87.9) & $5.58( \pm 3.92)$ & $11.98( \pm 12.41)$ & & \\
\hline Total & 312 & 35 (10.95) & 277 (89.05) & $5.63( \pm 3.86)$ & $12.16( \pm 13.06)$ & & \\
\hline
\end{tabular}

NS, not statistically significant 
Table 2: Difference between mean $\mathrm{dmft}$ and dmfs in primary teeth

\begin{tabular}{lllllll}
\hline & $N$ & Mean & Std. deviation & $t$ & $d f$ & $p$ value \\
\hline dmfs & 312 & 12.16 & 13.06 & 8.07 & 380.1 & $0.000^{*}$ \\
dmft & 312 & 5.63 & 3.86 & & & \\
\hline
\end{tabular}

*Statistically significant at $p \leq 0.05$

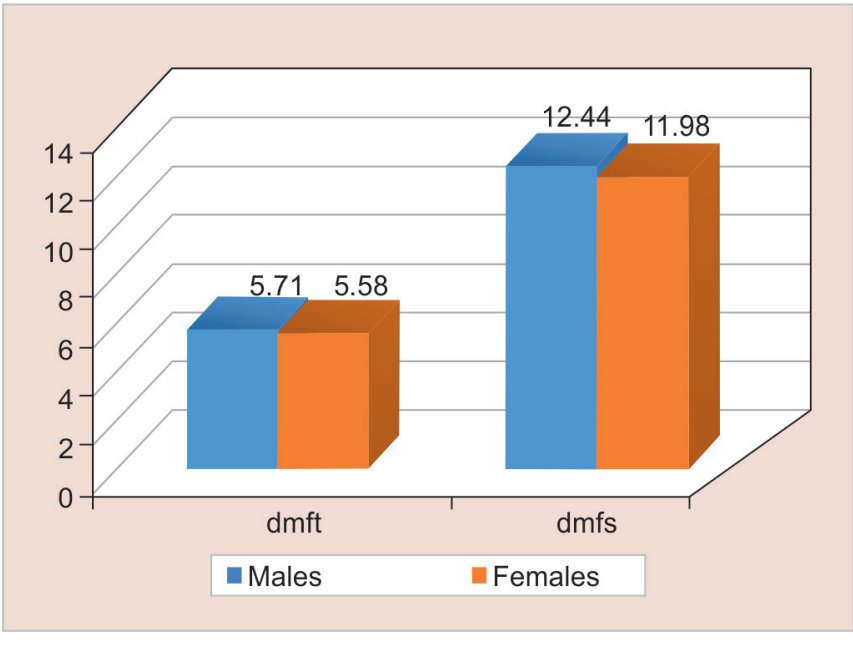

Fig. 2: Mean dmft and dmfs in relation to gender for primary teeth

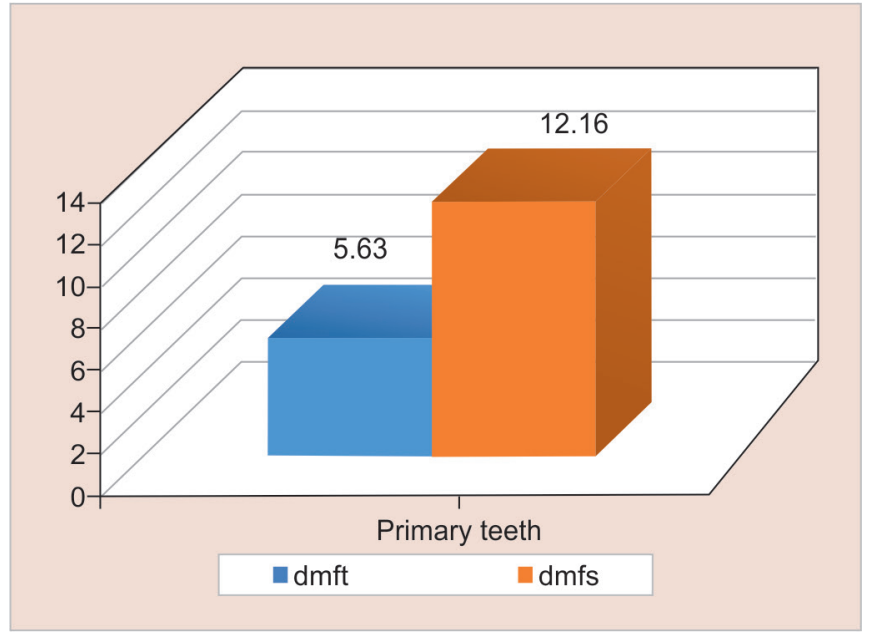

Fig. 3: Mean dmft and dmfs for primary teeth

Table 3: Mean dmft (decayed-missing-filled) in males and females for primary teeth

\begin{tabular}{llllll}
\hline & & & & \\
Gender & Decayed & Missing & Filled & Meandmft $( \pm S D)$ & $p$ value \\
\hline Males & $4.27( \pm 3.72)$ & $0.58( \pm 1.75)$ & $0.86( \pm 1.59)$ & $5.71( \pm 3.78)$ & $0.77 \mathrm{NS}$ \\
Females & $4.72( \pm 3.74)$ & $0.33( \pm 1.18)$ & $0.53( \pm 1.35)$ & $5.58( \pm 3.92)$ & \\
Total & $4.54( \pm 3.74)$ & $0.43( \pm 1.44)$ & $0.66( \pm 1.46)$ & $5.63( \pm 3.86)$ & \\
\hline
\end{tabular}

NS, not statistically significant

Table 4: Mean dmfs (decayed-missing-filled) in males and females for primary teeth

\begin{tabular}{llllll}
\hline & & & & & t test \\
\cline { 3 - 6 } Gender & Decayed & Missing & Filled & Mean dmfs $( \pm$ SD) & p value \\
\hline Males & $7.01( \pm 9.27)$ & $3.03( \pm 8.97)$ & $2.40( \pm 6.42)$ & $12.44( \pm 14.10)$ & $0.76 \mathrm{NS}$ \\
Females & $8.55( \pm 9.43)$ & $1.71( \pm 5.90)$ & $1.73( \pm 5.11)$ & $11.98( \pm 12.41)$ & \\
Total & $7.95( \pm 9.38)$ & $2.23( \pm 7.27)$ & $1.99( \pm 5.66)$ & $12.16( \pm 13.06)$ & \\
\hline
\end{tabular}

$\mathrm{NS}$, not statistically significant

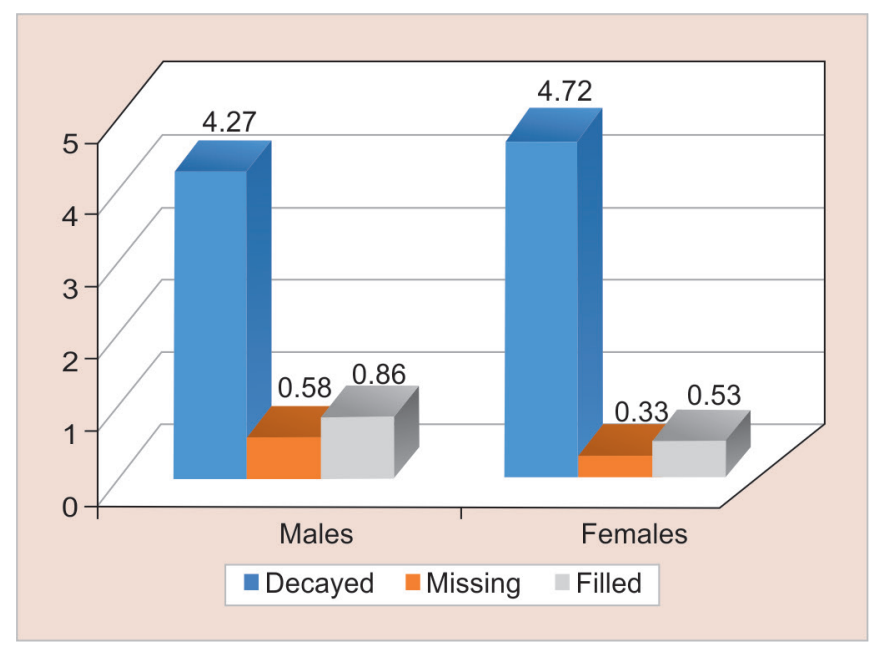

Fig. 4: Mean dmft in males and females for primary teeth

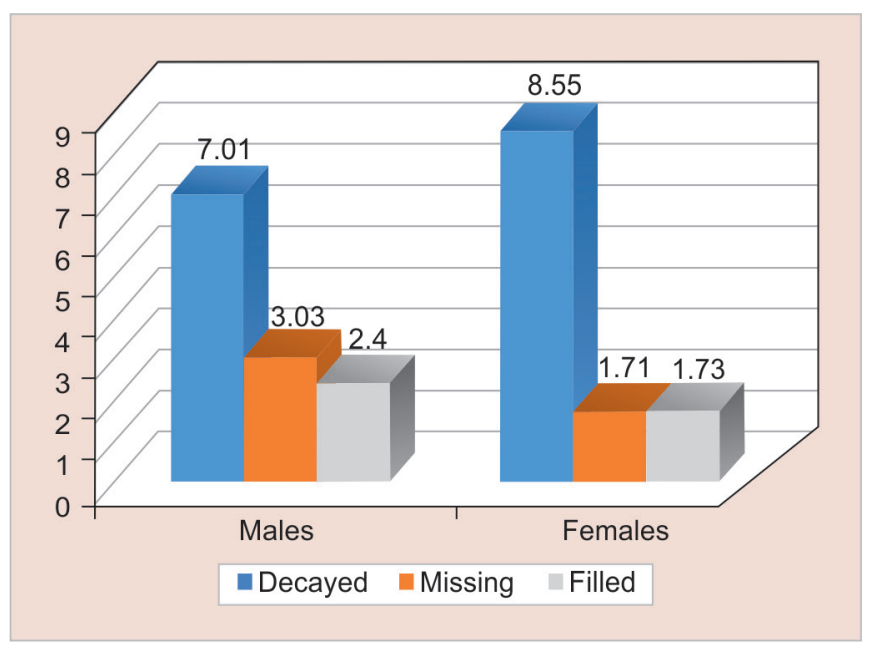

Fig. 5: Mean dmfs in relation to gender for primary teeth 
Table 5: Caries prevalence by individual primary teeth

\begin{tabular}{llllll}
\hline & \multicolumn{3}{c}{ Maxillary teeth } & & \multicolumn{2}{c}{ Mandibular teeth } \\
\cline { 2 - 3 } Tooth & Right (\%) & Left (\%) & & Right (\%) & Left (\%) \\
\hline Central incisor & 28 & 45 & & 1.7 & 2.6 \\
Lateral incisor & 17.7 & 19.7 & & 2.9 & 3.6 \\
Canine & 10.3 & 10.3 & & 7.4 & 6.4 \\
First molar & 45.2 & 42 & & 59 & 55.8 \\
Second molar & 50.3 & 46.8 & & 64.4 & 66 \\
\hline
\end{tabular}

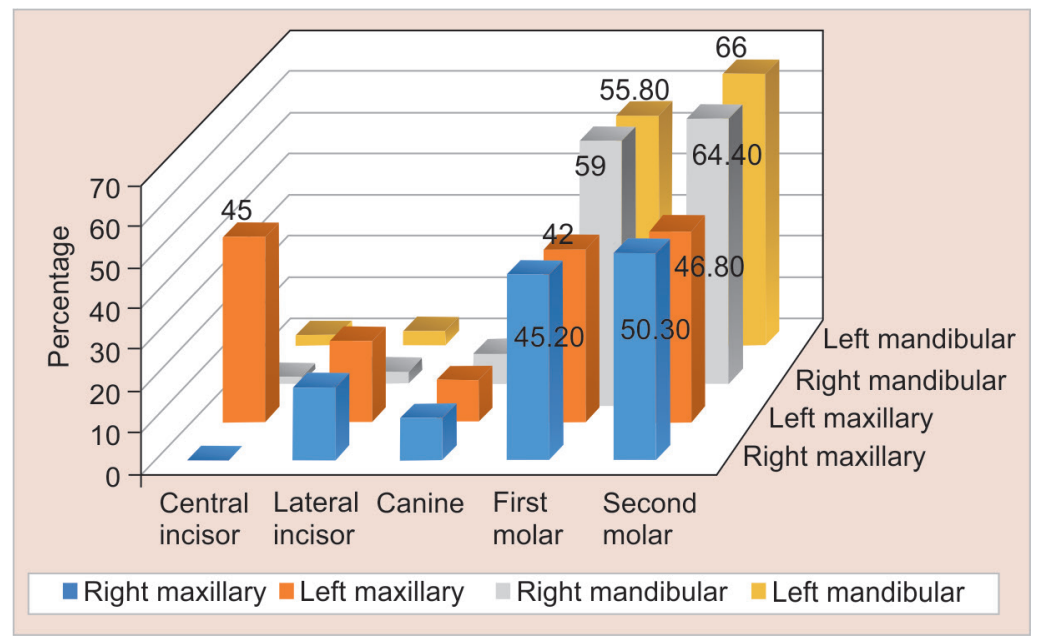

Fig. 6: Caries prevalence by individual primary teeth (graphical presentation)

Table 6: Prevalence of caries, mean DMFT, and DMFS in relation to gender for permanent teeth

\begin{tabular}{llllllll}
\hline Gender & No. of children & $\begin{array}{l}\text { Caries-free } \\
\text { children }(\%)\end{array}$ & $\begin{array}{l}\text { Children with } \\
\text { caries (\%) }\end{array}$ & DMFT $( \pm$ SD) & DMFS $( \pm S D)$ & $X^{2}$ & $p$ value \\
\hline Males & 122 & $94(77)$ & $28(23)$ & $0.36( \pm 0.76)$ & $0.40( \pm 0.95)$ & 6.39 & $0.011^{*}$ \\
Females & 190 & $167(87.9)$ & $23(12.1)$ & $0.19( \pm 0.61)$ & $0.33( \pm 1.28)$ & \\
Total & $312(100 \%)$ & $262(84)$ & $50(16)$ & $0.26( \pm 0.68)$ & $0.36( \pm 1.16)$ & \\
\hline
\end{tabular}

*Statistically significant at $p \leq 0.05$

Table 7: Mean DMFT (decayed-missing-filled) in males and females for permanent teeth

\begin{tabular}{llllll}
\hline & & & & Mean DMFT & t test \\
\cline { 4 - 6 } Gender & Decayed & Missing & Filled & $0.37( \pm 0.76)$ & $0.035^{*}$ \\
\hline Males & $0.30(0.67)$ & 0.00 & $0.07(0.42)$ & $0.19( \pm 0.61)$ & \\
Females & $0.19(0.61)$ & 0.00 & $0.01(0.07)$ & $0.26( \pm 0.68)$ & \\
Total & $0.23(0.63)$ & 0.00 & $0.03(0.27)$ & & \\
\hline
\end{tabular}

*Statistically significant at $p \leq 0.05$

Table 8: Mean DMFS (decayed-missing-filled) in males and females for permanent teeth

\begin{tabular}{|c|c|c|c|c|c|}
\hline \multirow[b]{2}{*}{ Gender } & \multirow[b]{2}{*}{ Decayed } & \multirow[b]{2}{*}{ Missing } & \multirow[b]{2}{*}{ Filled } & \multirow{2}{*}{$\begin{array}{l}\text { Mean DMFS } \\
( \pm S D)\end{array}$} & \multirow{2}{*}{$\frac{t \text { test }}{p \text { value }}$} \\
\hline & & & & & \\
\hline Males & $0.36(0.88)$ & 0.00 & $0.04(0.37)$ & $0.41( \pm 0.95)$ & $0.54 \mathrm{NS}$ \\
\hline Females & $0.32(1.28)$ & 0.00 & $0.01(0.07)$ & $0.33( \pm 1.28)$ & \\
\hline Total & $0.34(1.14)$ & 0.00 & $0.02(0.24)$ & $0.36( \pm 1.16)$ & \\
\hline
\end{tabular}

NS: not statistically significant 


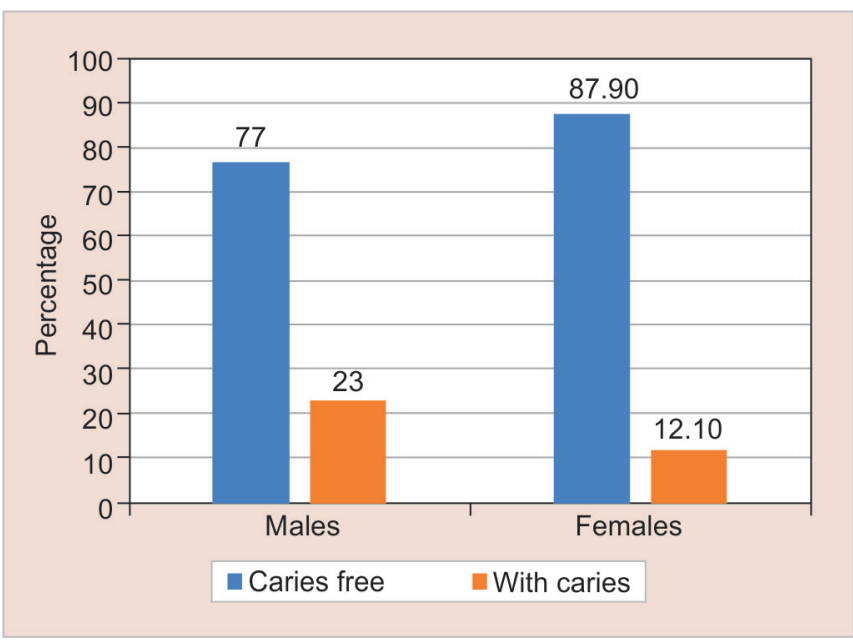

Fig. 7: Prevalence of caries in relation to gender for permanent teeth

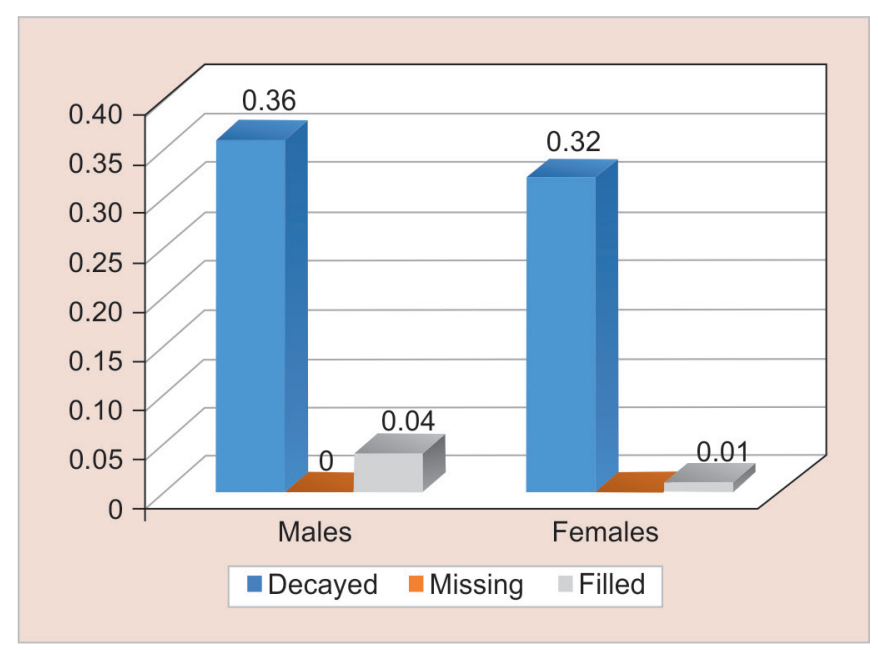

Fig. 9: Mean DMFS in relation to gender for permanent teeth

Among the maxillary teeth, decay prevalence was the highest in permanent central incisors (12.65\%), followed by permanent first molars (2.85\%). Among the mandibular teeth, the prevalence was highest in first permanent molars (4.65\%), followed by permanent central incisors (0.5\%) (Table 9, Fig. 10).

Concerning calibration and computation procedure for dental and oral health, a comparison between the outcomes of the investigators and the analysis was performed to decide the degree of uniformity among them. A satisfactory degree of uniformity was $85 \%$ or higher. ${ }^{15}$ Inter-and intra-examiner reliability extended from 0.75 to 0.86 , and from 0.93 to 0.98 , respectively.

\section{Discussion}

The aim of the present research was to decide the pervasiveness, seriousness, and pattern of dental decay in 6-7-year-old youngsters in military elementary schools in Jeddah, Kingdom of Saudi Arabia. The study was a part of an oral wellbeing advancement program in these schools to advance oral wellbeing in this chosen group of youngsters.

In our study, decay prevalence and dmft scores were found to be very high among the selected youngsters. Eighty-nine percent of the youngsters had decay and only $10.95 \%$ were decay-free.

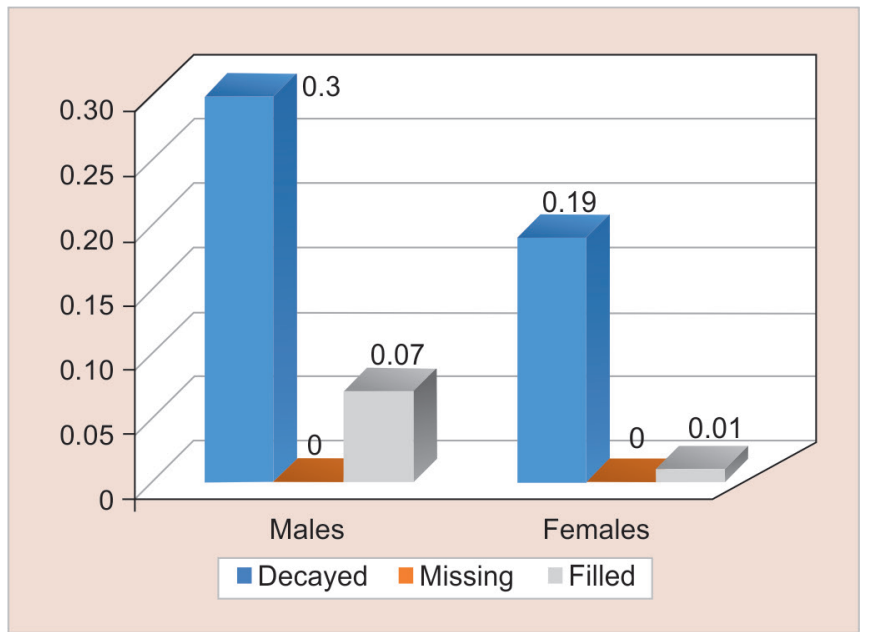

Fig. 8: Mean DMFT in relation to gender for permanent teeth

This agrees with the study done by AL-Malik and Rehbini, who showed that decay was diagnosed in $96 \%$ of the youngsters and only $4 \%$ were clinically decay-free. ${ }^{17}$ There was no notable difference between decay prevalence and $\mathrm{dmft}$ in relation to gender.

The decay segment was the primary part of dmft scores, which demonstrated a high level of untreated decay and a high treatment requirement for these youngsters. A past report has likewise revealed decay as the notable component of dmft scores. ${ }^{18}$ The current study showed a dmft score of 5.63, while AL-Malik and Rehbini study revealed a dmft score of $8.06 .{ }^{17}$

The information on decay design decides the proper treatment planning for these youngsters. The investigation demonstrated the event of decay in both anterior and posterior teeth in the majority of the boys and girls. The pervasiveness of decay in molars was for the most part reciprocal. The teeth most influenced via decay were mandibular primary second molars (64.4\% and 66\%) and the least influenced were mandibular primary central incisors $(1.7 \%$ and $2.6 \%$ ). The decay predominance was commonly higher in the mandibular primary teeth than similar teeth in the maxilla; this is steady with the discoveries of AL-Malik and Rehbini. ${ }^{17}$

The high predominance of decay in this chosen populace can likewise be identified with poor oral cleanliness rehearses, ill-advised dietary propensities, just as poor dental mindfulness and absence of dental information among those youngsters. Extra factors-for example, late first dental visits for standard registration and beginning brushing late, which is normal in Saudi-may likewise be in charge of the high decay predominance. ${ }^{19}$

Dental examination is accessible free of charge for this populace; in any case, the dimension of dental decay is high. This could be attributed to the far dental appointment in the clinic or the patient had a bad dental encounter. Standard dental visits are important to improve oral wellbeing. Routine dental visits for normal check-up are not regular in Kingdom of Saudi Arabia; numerous guardians took their youngsters to the dental specialist just when they are in agony. ${ }^{18,19}$

Although dental awareness is increasing these days in many schools and public areas, still the spread of dental decay is high owing to the decreased dental knowledge of parents.

There is an expanded interest to begin instructive projects for new and eager moms to build their dental learning and to offer counsel to limit cariogenic bites and beverages, to begin oral 


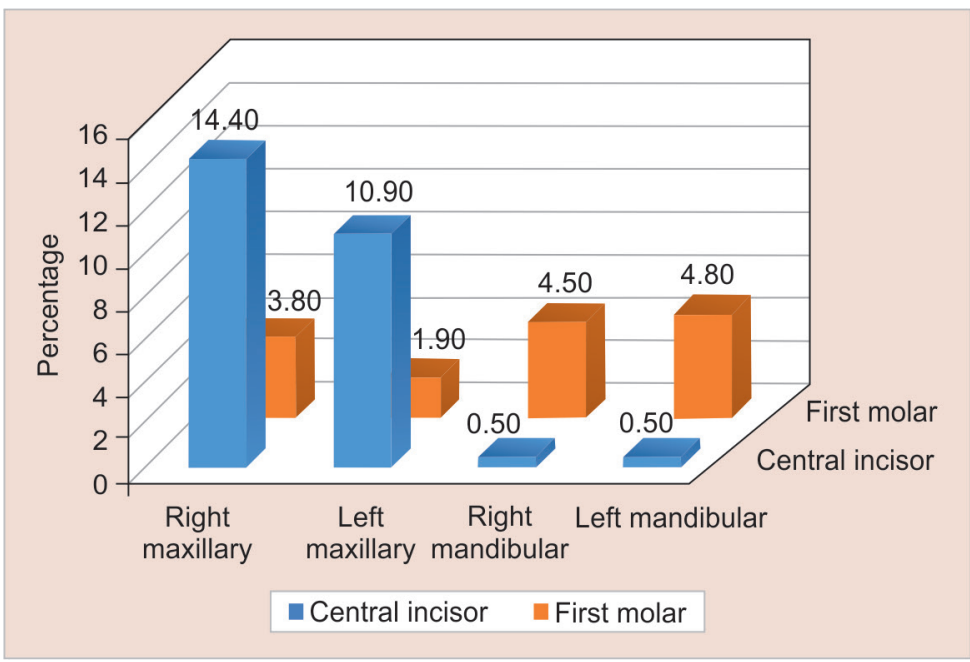

Fig. 10: Caries prevalence by individual permanent teeth (graphical presentation)

Table 9: Caries prevalence by individual permanent teeth

\begin{tabular}{llllll}
\hline & \multicolumn{3}{c}{ Maxillary teeth } & & \multicolumn{2}{c}{ Mandibular teeth } \\
\cline { 2 - 3 } Tooth & Right (\%) & Left (\%) & & Right (\%) & Left (\%) \\
\hline $\begin{array}{l}\text { Central } \\
\text { incisor }\end{array}$ & 14.4 & 10.9 & & 0.5 & 0.5 \\
First molar & 3.8 & 1.9 & & 4.5 & 4.8 \\
\hline
\end{tabular}

cleanliness early, and to get dental check- ups for their youngsters early. Additionally, we ought to consider the preparation of dental assistants (e.g., dental advisors, dental hygienists, and dental instructors) to help in the control and prevention of dental decay.

\section{Conclusion}

The prevalence of dental decay was high among the present study sample. There is a vast need to reduce dental decay by increasing dental awareness for youngsters and their parents by implementing a preventive and oral hygiene promotion program.

\section{Clinical Significance}

Age has an important role in evaluating decay prevalence and dmft/ $\mathrm{dmfs} / \mathrm{DMFT} / \mathrm{DMFS}$ indices. On the basis of age, caries is prevalent in 6-7-year-old youngsters and the $\mathrm{dmft} / \mathrm{dmfs} / D M F T / D M F S$ indices resulted in high values.

\section{Acknowledgments}

The authors sincerely acknowledge Drs. Muhammad Saifaddin, Khalid Altaf, Muath Bentan, and Eyad Suqati, Dental Interns, Faculty of Dentistry, Ibn Sina National College for Medical Studies, for their help in clinical examination of the children.

\section{References}

1. Benjamin RM. Oral health: the silent epidemic. Public Health Rep 2010;125(2):158-159. DOI: 10.1177/003335491012500202.

2. Bagramian RA, Garcia-Godoy F, et al. The global increase in dental caries. A pending public health crisis. Am J Dent 2009;22(1):3-8.

3. Al-Malik MI, Holt RD, et al. Prevalence and patterns of caries, rampant caries, and oral health in two- to five-year-old children in Saudi Arabia. J Dent Child (Chic) 2003;70(3):235-242.

4. Zhang S, Liu J, et al. Dental caries status of Bulang preschool children in Southwest China. BMC Oral Health 2014;14:16. DOI: 10.1186/14726831-14-16.
5. Prakasha Shrutha S, Vinit GB, et al. Feeding practices and early childhood caries: a cross-sectional study of preschool children in Kanpur District India. ISRN Dent 2013;2013:275193. DOI: 10.1155/2013/275193.

6. Thekiso M, Yengopal V, et al. Caries status among children in the West Rand District of Gauteng Province, South Africa. SADJ 2012;67(7): 318-320.

7. Pitts NB, Boyles J, et al. The dental caries experience of 5-year-old children in Great Britain (2005/6). Surveys co-ordinated by the British Association for the study of community dentistry. Community Dent Health 2007;24(1):59-63.

8. Congiu G, Campus G, et al. Early childhood caries and associated determinants: a cross-sectional study on Italian preschool children. J Public Health Dent 2014;74(2):147-152. DOI: 10.1111/jphd.12038.

9. Locker D. Disparities in oral health-related quality of life in a population of Canadian children. Community Dent Oral Epidemiol 2007;35(5):348-356. DOI: 10.1111/j.1600-0528.2006.00323.x.

10. Holst $D$, Schuller AA, et al. Caries in populations-a theoretical, causal approach. Eur J Oral Sci 2001;109(3):143-148. DOI: 10.1034/j.16000722.2001.00022.x.

11. AlAgili DE, Alaki SM. Can socioeconomic status indicators predict caries risk in school children in Saudi Arabia? A cross-sectional study. Oral Health Prev Dent 2014;12(3):277-288.

12. Koch G, Martinsson T. Socio-odontologic investigation of school children with high and low caries frequency. I. Socio-economic background. Odontol Revy 1970;21(2):207-228.

13. Farsi N, Merdad L, et al. Caries risk assessment in preschool children in Saudi Arabia. Oral Health Prev Dent 2013;11(3):271-280.

14. Wyne AH. Caries prevalence, severity, and pattern in preschool children. J Contemp Dent Pract 2008;9(3):24-31. DOI: 10.5005/jcdp9-3-24.

15. World Health Organization (WHO). Oral Health Surveys: Basic Methods, 6th ed., Geneva: WHO; 2013.

16. Pitts NB, Evans DJ, et al. British Association for the Study of Community Dentistry (BASCD) diagnostic criteria for caries prevalence surveys1996/97. Community Dent Health 1997;14(Suppl 1):6-9.

17. AL-Malik MI, Rehbini YA. Prevalence of dental caries, severity, and pattern in age 6 to 7-year-old children in a selected community in Saudi Arabia. J Contemp Dent Pract 2006;7(2):46-54. DOI: 10.5005/ jcdp-7-2-46.

18. Al-Amoudi N, Salako NO, et al. Caries experience of children aged 6-9 years in Jeddah, Saudi Arabia. Int J Paediatr Dent 1996;6(2):101-105. DOI: 10.1111/j.1365-263X.1996.tb00220.x.

19. Nainar SM, Wyne AH. Caries pattern of high caries preschool children attending a dental clinic in Riyadh. Saudi Dent J 1998; 10:80-85. 